\title{
O Papel das Didascálias no Trabalho de Tradução de Les Cenci, de Antonin Artaud
}

\section{The Role of Stage Directions in the Translation Work of Les Cenci, by Antonin Artaud}

Neste teatro, toda criação provém da cena, encontra sua tradução e suas origens num impulso psíquico secreto que é a Palavra anterior às palavras (ARTAUD 2006: 63).

Rodrigo lelpo*

Professor de Língua e Literatura Francesa do Departamento de Letras Neolatinas da Universidade Federal do Rio de Janeiro. E-mail: rodrigoielpo@letras.ufrj.br

TradTerm, São Paulo, v.38, fevereiro/2021, p. 46-60

Número Especial - III JOTA

www.revistas.usp.br/tradterm 
Resumo: Ao propor uma análise comparativa entre "Teatro oriental e teatro ocidental" em O teatro e seu duplo (1993), Antonin Artaud expõe sua conhecida crítica em relação à submissão do espetáculo ao texto dramático. Segundo Artaud, a tradição ocidental faria do teatro um "simples reflexo material do texto", tornando problemática a própria separação do "teatro da ideia de texto realizado". Condicionada por esse tipo de afirmação, Les Cenci (2011), escrita por Artaud e encenada pela primeira vez em 1935 sob sua direção, teria causado certo incômodo entre parte dos seus admiradores. Para estes, haveria uma contradição entre as posições teóricas do autor e a proposta cênica de um espetáculo que, no final das contas, orbitaria em torno de um texto. Ao problematizar esse tipo de recepção num prefácio escrito para a peça, Michel Corvin (2011) chama atenção para a relevância que as indicações cênicas teriam na obra, o que o leva a subverter a importância das didascálias em relação ao conjunto de réplicas. Ao funcionarem como uma partitura que visaria abrir o texto para sua dimensão propriamente teatral, essas informações acabariam por deslocá-lo de sua pretensa centralidade. O objetivo deste artigo é refletir sobre o papel dessas rubricas no trabalho de tradução de Les Cenci, procurando entender em que medida elas permitiriam operar uma prática tradutória que levasse em consideração as especificidades da teatralidade já presente no próprio suporte escrito da peça.

Palavras-chave: Artaud; Les Cenci; teatro; crueldade, tradução.

Abstract: In proposing a comparative analysis between "Oriental theater and Western theater" in The theater and its double (1993), Antonin Artaud exposes his wellknown criticism regarding the submission of the play to the dramatic text. According to Artaud, the western tradition would make the theater a "simple material reflection of the text", making the separation of "theater from the idea of the realized text" problematic. Conditioned by this kind of statement is that Les Cenci (2011), written by Artaud and staged for the first time in 1935 under his direction, would cause some discomfort among some of his admirers. For these, there would be a contradiction between the author's theoretical positions and the scenic proposal of a show that, in the end, would orbit around a text. Questioning this type of reception, in a preface written for the play, Michel Corvin (2011) draws attention to the relevance that scenic indications would have in the work, subverting the importance of stage directions in relation to the set of replicas. Functioning as a score aiming to open the text to its properly theatrical dimension, this information would end up displace it from its supposed centrality. The purpose of this paper is to reflect on the role of these stage directions in Les Cenci's translation work, trying to understand to what extent they would allow to operate a translation practice that considers the specificities of theatricality that would already be present in the written support of the play itself.

Keywords: Artaud; Les Cenci; theatre; cruelty; translation.

TradTerm, São Paulo, v.38, fevereiro/2021, p. 46-60

Número Especial - III JOTA

www.revistas.usp.br/tradterm 
Enunciada em "Sobre o Teatro de Bali", texto da coletânea $O$ teatro $e$ seu duplo, a passagem citada acima, em forma de epígrafe, remete ao projeto teatral de Artaud. É preciso, nas palavras de Jacques Derrida (1995: 161) em artigo dedicado ao autor, atentar para o fato de que,

Não se trata de construir uma cena muda, mas uma cena cujo clamor ainda não se apaziguou na palavra. A palavra é o cadáver da palavra psíquica e é preciso reencontrar, com a linguagem da própria vida, "a Palavra anterior às palavras". O gesto e a palavra ainda não estão separados pela lógica da representação. ${ }^{1}$

A intervenção de Derrida serve para que possamos relançar o problema da relação entre texto e teatro em Artaud, deslocando a ideia de que o rebaixamento do primeiro deveria levar a um rebaixamento da palavra como um todo. Ou seja, trata-se, antes, de propor uma alteração do status da palavra, para que esta, como sugere Derrida, possa operar toda "a sua sonoridade, a sua entoação, a sua intensidade, o grito que a articulação da língua e da lógica ainda não calou totalmente” (DERRIDA 1995: 161). São essas premissas que precisamos tensionar, como aqui procuro argumentar, com a leitura que deve pautar a tradução de Les Cenci, peça de autoria de Artaud. São elas que possibilitam nuançar o que nos diz Anne Ubersfeld em Para ler o teatro:

Gostaríamos de lembrar aqui que a moderna desvalorização da palavra no teatro, na esteira de Artaud, é uma atitude singularmente paradoxal quando se pensa em todo o esforço do pensamento contemporâneo para mostrar o quanto a maior parte das grandes atividades humanas depende da linguagem. Talvez valesse a pena lembrar que o teatro é precisamente o lugar onde se pode ver, analisar e compreender a relação da palavra com o gesto e a ação (UBERSFELD 2005: 87).

Se acompanharmos as reflexões de Derrida, parece possível pensar não propriamente em uma "desvalorização da palavra", mas, insisto, em um deslocamento, ao menos no que tange ao caso específico de Les Cenci. Apresentada pela primeira vez em 1935 com direção do próprio Artaud, essa

\footnotetext{
1 Em "O teatro da crueldade e o fechamento da representação", de onde foi retirada essa citação, Derrida propõe uma aproximação entre o status da palavra e da linguagem em Artaud com as reflexões que Freud desenvolveria em sua teoria dos sonhos.
}

TradTerm, São Paulo, v.38, fevereiro/2021, p. 46-60

Número Especial - III JOTA

www.revistas.usp.br/tradterm 
peça trata da violência de um incesto sem consentimento cometido pelo velho Cenci em relação a Béatrice, sua filha, e o parricídio derivado de tal ato. ${ }^{2}$

Baseada num fato histórico, mas escrita em diálogo com a tragédia homônima de Shelley e uma narrativa breve de Stendhal, a peça marca uma das raras intervenções do teórico da crueldade no campo da escrita dramatúrgica, mesmo se, em suas próprias palavras, “ainda não são o Teatro da Crueldade, mas o preparam" (ARTAUD 2004: 639). ${ }^{3,4}$ Essa afirmação encontra-se justificada em outro comentário que aparece no mesmo texto da citação anterior, publicado em 1935 na revista La Bête Noire. Neste, Artaud diz acreditar ser esta "a primeira vez, pelo menos aqui na França, que se lidará com um texto de teatro escrito em função de uma encenação" (ARTAUD 2004: 639). ${ }^{5}$ Essa passagem torna evidente a inversão proposta e defendida em diversos textos de $O$ teatro e seu duplo (2006), segundo a qual se tratava não mais de submeter a encenação ao texto, mas seu contrário. Desse modo, a simples leitura que se queira fazer de Les Cenci deve prestar atenção ao seguinte alerta feito por Alain Virmaux (2009: 91): “na medida em que está circunscrito ao papel, é um texto que oferece ao leigo a mesma significação de uma partitura musical. Na falta da orquestração que a representação cênica introduzia, é preciso abordá-lo com certas precauções". Substituindose a figura do leitor pela do tradutor desse texto, torna-se, então, essencial desdobrar a observação de Virmaux sob a forma de uma questão: que precauções seriam essas? Traduzir Les Cenci obriga-nos antes de tudo a mapear o conjunto dessas questões em diálogo com os planos formal e teórico pensados por Artaud. Dito de outro modo, para a elaboração das possíveis estratégias tradutórias da peça, seria preciso refletir sobre as especificidades da teatralidade de Les Cenci a partir das reflexões de seu autor sobre essa obra e o teatro em geral.

\footnotetext{
${ }^{2}$ Cláudio Willer chama atenção para a recorrência do tema do incesto em Artaud e o quanto ele está ligado à vida familiar do autor: "Outro tema constante na sua obra, a fascinação pelo incesto, também teve relação com seu ambiente familiar, inclusive a trágica e prematura morte da sua irmã, Germaine, e seu pai autoritário [...]" (WILLER 1983: 7-8).

${ }^{3}$ Todas as traduções dos textos estrangeiros citados neste artigo são de minha autoria.

4 "ne sont pas encore le Théâtre de la Cruauté, mais ils le préparent."

5 "la première fois, tout au moins ici en France, que l'on aura affaire à un texte de théâtre écrit en fonction d'une mise en scène."
}

TradTerm, São Paulo, v.38, fevereiro/2021, p. 46-60

Número Especial - III JOTA

www.revistas.usp.br/tradterm 
Ao propor uma análise comparativa entre "Teatro oriental e teatro ocidental" em $O$ teatro e seu duplo, Artaud (2006: 75) expõe sua conhecida crítica em relação à dependência do espetáculo em relação ao texto dramático. Segundo Artaud, a tradição ocidental faria do teatro um "simples reflexo material do texto", tornando problemática a própria separação do "teatro da ideia de texto realizado". Condicionada por esse tipo de afirmação, a apresentação de Les Cenci teria causado certo incômodo entre parte dos admiradores de Artaud. Para estes, haveria uma contradição entre as posições teóricas do autor e dramaturgo e a proposta cênica de um espetáculo que, no final das contas, orbitaria em torno de um texto, escrito "sob a dupla fiança 'literária' de Shelley e de Stendhal" (VIRMAUX 2009: 88). ${ }^{6}$ Ao problematizar esse tipo de recepção e aproximar-nos da questão que aqui nos interessa, num prefácio escrito para a peça, Michel Corvin (2011: 11) chama atenção para a relevância que as indicações cênicas teriam na obra ao subverter a importância das didascálias em relação ao conjunto de réplicas. Ao funcionarem como uma partitura que visaria abrir o texto para sua dimensão propriamente teatral, essas informações acabariam por deslocá-lo de sua pretensa centralidade. Dessa forma, Corvin lança uma pista importante sobre o papel que essas rubricas poderiam ter no trabalho de tradução de Les Cenci, permitindo-nos entender em que medida elas permitiriam operar uma prática tradutória que levasse em consideração as especificidades da teatralidade que já estaria presente no próprio suporte escrito da peça. Essa posição vai ao encontro das pesquisas de Luiz Fernando Ramos a respeito do lugar das didascálias no texto dramático. Em $O$ parto de Godot e outras encenações imaginárias, Ramos (1999: 17) considera que,

o texto da rubrica pode ser considerado, contemporaneamente, o registro literário de uma certa poética cênica, o vestígio ou a marca de um método. 0 estilo de cada encenador e, ou, dramaturgo, quando exerce essa condição de montador de um espetáculo imaginário, estará estampado nas didascálias.

\footnotetext{
${ }^{6}$ Ao comentar o fracasso de Les Cenci, Susan Sontag aponta a dissimetria entre teoria e prática como traço da carreira de Artaud. Para a crítica, "ele exerceu influência através de suas ideias sobre o teatro, sendo uma parte constituinte da autoridade destas ideias precisamente a sua inabilidade de colocá-las em prática" (SONTAG 1986: 40-41).
}

TradTerm, São Paulo, v.38, fevereiro/2021, p. 46-60

Número Especial - III JOTA

www.revistas.usp.br/tradterm 
É esse espetáculo imaginário que é preciso perscrutar através das rubricas para que o texto possa ocupar seu real lugar na peça de Artaud, na qual "[a] iluminação, assim como os gestos, valerão também como uma linguagem, e a luz, nesse esforço em direção a uma linguagem teatral única, virá a todo instante juntar-se aos barulhos" (ARTAUD 2004: 641). ${ }^{7}$ Esse comentário, proferido numa apresentação da peça publicada no jornal Le Figaro em maio de 1935, mostra claramente a intenção do autor em aproximar Les Cenci dos pressupostos do teatro da crueldade. Segundo o primeiro manifesto desse teatro, publicado dois anos antes da apresentação de Les Cenci, trata-se de construir o espetáculo "tendo tomado consciência dessa linguagem no espaço, linguagem de sons, de gritos, de luzes, de onomatopeias [...]" (ARTAUD 2006: 102). O problema, contudo, é que o próprio Artaud havia afirmado, como vimos mais acima, que Les Cenci apenas preparava o caminho para o teatro da crueldade, o que deixa pressupor, de certo modo, a não realização total de seu projeto. ${ }^{8} \mathrm{Em}$ conjunto com a própria recepção deceptiva em relação às apresentações da montagem, essa posição ambígua do autor não deixa de se relacionar com o papel de destaque que o texto parece ter no espetáculo, em aparente discordância com as teorizações que afirmavam que "ao lado desse sentido lógico, as palavras serão tomadas num sentido encantatório, verdadeiramente mágico - por sua forma, suas emanações sensíveis e já não apenas por seu sentido" (ARTAUD 2006: 146). Corvin chama atenção para o fato de "que Artaud, ao adaptar Shelley, teve consciência disso", o que aparece ao longo da própria peça e que ficaria marcado, afirma o crítico, na mudança de ritmo "a partir da cena 3 (a cena do banquete) do primeiro ato" (CORVIN 2011: 139). ${ }^{9}$ Porém,

\footnotetext{
7 "Les éclairages, comme les gestes, vaudront aussi comme un langage, et la lumière, dans cet effort vers un langage théâtral unique, viendra à tout instant rejoindre les bruits."

${ }^{8}$ No segundo manifesto do Teatro da crueldade, publicado sob forma de brochura em 1933, Artaud havia afirmado que a primeira peça do teatro da crueldade seria $A$ conquista do México, a qual, segundo as palavras do próprio autor, "porá em cena acontecimentos e não seres humanos" (ARTAUD 2006: 148). Quanto a Les Cenci, Artaud expressa sua frustração em relação ao não cumprimento de seu projeto teatral na passagem de uma de suas cartas, remetida em 1935 a Jean-Louis Barrault: "se em Os Cenci nada foi fixado definitivamente foi porque Os Cenci escapava, em parte, dos limites do teatro que quero fazer e porque eu, no final das contas, fui desbarrancado pela imensidão da tarefa que havia me imposto" (ARTAUD 1995: 126)

9 “qu'Artaud, en adaptant Shelley, en a pris conscience [...] à partir de la scène 3 (la scène du banquet) de l'acte I."
}

TradTerm, São Paulo, v.38, fevereiro/2021, p. 46-60

Número Especial - III JOTA

www.revistas.usp.br/tradterm 
aparentemente, essa mudança não chegou a ser suficiente diante da expectativa que havia sido gerada. Para o espectador em dia com o desenvolvimento das posições teóricas de Artaud, Les Cenci pareceu longe do que ele prometera, por exemplo, em uma de suas "Cartas sobre a linguagem". Segundo esta, "trata-se de nada menos do que mudar o ponto de partida da criação artística e de subverter as leis habituais do teatro. Trata-se de substituir a linguagem articulada por uma linguagem de natureza diferente" (ARTAUD 2006: 129).

Apesar disso, se promovermos um ligeiro desvio na leitura que normalmente se faz dessa obra, essa aparente defasagem entre posição teórica e mise en scène parece se resolver em parte, ao menos num plano ideal, sob dois aspectos. O primeiro, observado pela crítica, no que concerne ao tema abordado, pois,

A transgressão dos grandes interditos (incesto, estupro e parricídio) dos quais a peça de Shelley se alimentou, contribuiu para a decisão de Artaud, que levou essa transgressão, condensada em um núcleo de crimes puros, a um nível de extrema desmesura (CORVIN 2011: 29). ${ }^{10}$

O segundo, justamente pelas informações dispostas pelas rubricas, as quais indicariam essa aproximação mais estreita entre as ideias de Artaud para o teatro e a encenação proposta por ele para Les Cenci. Assim, se as duas primeiras cenas parecem não sair do impasse criado pela supremacia do texto, Corvin, ao chamar nossa atenção para a transformação rítmica operada na passagem para a terceira cena do primeiro ato, sugere que “é preciso prestar atenção à precisão das indicações de tempo, de luz, de sonoplastia [...]" (CORVIN 2011: 140). ${ }^{11}$ Do mesmo modo, deve-se atentar para o "lugar concedido ao paralinguístico (gritos, risos, gemidos, tosses, suspiros)" e à “incessante mobilidade em gestos e em movimentos, mesmo em agitação

10 "La transgression des interdits majeurs (inceste, viol et parricide), dont se nourrit la pièce de Shelley, a contribué à décider Artaud qui a porté cette transgression, condensée en un noyau de crimes purs, à un degré extrême de démesure."

11 "il faut prêter attention est la précision des indications de tempo, de lumière et de bruitage [...]."

TradTerm, São Paulo, v.38, fevereiro/2021, p. 46-60

Número Especial - III JOTA

www.revistas.usp.br/tradterm 
[...]" (CoRvin 2011: 141). ${ }^{12}$ Nesse sentido, é crucial observar a mudança do grau de importância das rubricas das duas primeiras cenas do primeiro ato não apenas em relação ao terceiro, mas a todo o resto da peça. Para um breve comparativo, basta observar o seguinte em relação à quantidade de didascálias aí presentes:

- Cena I do primeiro ato: 7 pequenas rubricas.

- Cena II do primeiro ato: 3 pequenas rubricas.

- Cena III do primeiro ato: 29 rubricas, algumas ocupando mais da metade da página.

- Cena I do segundo ato: 21 rubricas.

- Cena I do terceiro ato: 14 rubricas.

- Cena III do quarto ato (última cena): 15 rubricas.

Esse salto, que não é apenas quantitativo, mas também qualitativo, pode ser notado na rubrica que abre a terceira cena do primeiro ato. Após sugerir uma aproximação entre a cena do banquete que se seguirá e "As Bodas de Caná"13, quadro de Veronese retratando a passagem bíblica da transmutação de água em vinho realizada por Jesus, Artaud expõe a máquina semiótica que deveria comandar a montagem, engendrando, por meio da rubrica, a passagem do texto ao espetáculo:

Cortinas púrpuras voam ao vento, caem em pesadas dobras sobre as muralhas. E subitamente, sob uma cortina que se eleva, explode uma cena de orgia furiosa pintada como em trompe l'œil. Os sinos de Roma soam com força, mas, secretamente, em harmonia com o ritmo impetuoso do banquete. As vozes se amplificam, adquirindo um tom grave ou estridente, como clarificadas pelos sinos. De tempos em tempos, um som volumoso se estende e retine, como se parado por um obstáculo que o fizesse percutir em arestas afiadas (ARTAUD 2011: 59-60). ${ }^{14}$

\footnotetext{
12 "la place accordée au paralinguistique (cris, rires, sanglots, toux, soupirs) [...] l'incessante mobilité en gestes et en mouvements voire en agitation [...]."

${ }^{13}$ Marcando a inserção da cena no regime da crueldade, Artaud faz, porém, a ressalva de que apesar da semelhança evocada, a cena que deseja construir opera em um modo muito mais bárbaro que a que se dá a ver no quadro do pintor italiano.

14 "Des rideaux pourpres volent au vent, retombent en plis lourds sur les murailles. Et tout à coup, sous un rideau soulevé, éclate une scène d'orgie furieuse, peinte comme en trompe

TradTerm, São Paulo, v.38, fevereiro/2021, p. 46-60

Número Especial - III JOTA www.revistas.usp.br/tradterm
} 
Emitidos em ritmos e temporalidades distintos, o conjunto dos diferentes signos descritos por Artaud engendra "uma verdadeira polifonia informacional” (BARTHES 2002: 508) ${ }^{15}$, expressão que Roland Barthes usará para descrever a própria noção de teatralidade.

Falando diretamente à sensibilidade do espectador e não mais ao seu intelecto, toda essa máquina expressiva sugerida pela rubrica visava, assim, intensificar "a violência e a 'loucura' dos atos das personagens dessas peças que desafiam os valores considerados 'morais' [...]" (Felícıo 1996: 130). Ou seja, submetendo o texto a esse circuito cênico exposto pelas didascálias, Artaud pretendia, pode-se dizer, lograr arrastar o que poderia aparecer como linguagem puramente conceitual ao que seria o espaço próprio à cena da crueldade. Nesse espaço, “tudo no espetáculo visa à expressão por meios físicos que engajam tanto o espírito quanto a sensibilidade" (ARTAUD V 1964: $41)^{16}$. Assim, nessa outra passagem em que o velho Cenci ameaça Béatrice, Artaud orienta que as vozes dos convivas se dissolvam completamente na forma de um grito coletivo, ao mesmo tempo em que os corpos devem mover os signos de uma angústia exacerbada por meio de movimentos desconexos: “Aqui, toda a gente, como se tivesse recebido um forte soco no estômago, respira e em seguida exala um grande grito; depois todos se lançam em desordem em direção a todas as saídas" (ARTAUD 2011: 67). ${ }^{17}$

Corpos e vozes. Em Les Cenci, aí parece recair grande parte da atenção que Artaud dedica ao devir espetáculo do texto sugerido pelas didascálias, pois, como indica Vera Lúcia Felício (1996: 30), para o teatro da crueldade, “a linguagem específica do corpo é a linguagem física, dos gritos de um homem ocupado em refazer sua Vida”. Dessa forma, as vozes misturam-se a ruídos como a propor uma espécie de desfazimento do homem naquilo que ele tem de mais racional, e cujo sintoma seria a própria fala:

l'œil. Les cloches de Rome sonnent à toute volée, mais en sourdine, en accord avec le rythme tourbillonnant du festin. Les voix s'amplifient, prenant la tonalité grave ou suraiguë et comme clarifiée des cloches. De temps en temps un son volumineux s'étale et fuse, comme arrêté par un obstacle qui le fait rejaillir en arêtes aiguisées."

15 "[...] une véritable polyphonie informationnelle."

16 "'[...] tout dans le spectacle vise à l'expression par des moyens physiques qui engagent aussi bien l'esprit que la sensibilité."

17 "Ici, toute la foule, comme si elle avait reçu un grand coup de poing dans l'estomac, respire et exhale ensuite un grand cri; puis elle s'élance en désordre vers toutes les sorties."

TradTerm, São Paulo, v.38, fevereiro/2021, p. 46-60

Número Especial - III JOTA

www.revistas.usp.br/tradterm 
Ninguém mais sabe gritar na Europa, e especialmente os atores em transe não sabem mais dar gritos. Quanto às pessoas que só sabem falar e que se esqueceram de que tinham um corpo no teatro, também se esqueceram de usar a garganta. Reduzidas a gargantas anormais, não é nem mesmo um órgão mas sim uma monstruosa abstração que fala: os atores, na França, agora só sabem falar (ARTAUD 2006: 160).

Diversas didascálias sugerem, assim, essa simetria entre vozes e sons de todo tipo, abrindo a garganta do homem à potência do ruído na mesma medida em que confere uma voz às coisas, inserindo o mundo todo numa espécie de grande jogo de vocalizações: “Cenci vai até a mesa e enche uma nova taça de vinho. Diversas chamas se apagam de repente. Ouvimos a voz dos sinos tornar-se cavernosa [...]. Algo como um som de viola vibra levemente e muito alto" (ARTAUD 2011: 69). ${ }^{18}$ o que importa, e que percebemos nessas passagens, é impedir essa captura por uma razão conceitual que faz com que esquecidos de seus corpos, os atores "agora só sabem falar", como afirma Artaud. Contra isso, o grito, mas também a música, se oferecem como possibilidade de devolver o homem ao homem nesse processo de dissolução: “A música se eleva. Uma espécie de voz humana desesperada mistura-se a seu ritmo obsedante" (ARTAUD 2011: 122). ${ }^{19}$

Outro dado importante é que em conjunto com as outras rubricas expostas até aqui, a passagem acima aponta para o lugar do exagero na obra, o qual se apropria do tom trágico em diversos momentos da peça, permitindo a Artaud colocar em prática parte do programa que ele havia exposto em seu primeiro manifesto, qual seja, "Um ou vários melodramas românticos em que a inverossimilhança se tornará um elemento ativo e concreto de poesia” (ARTAUD 2006: 115). Nesse sentido, a atenção à construção das rubricas em Les Cenci é capital para a compreensão do que parece ser uma estratégia de efetuação dos pressupostos da crueldade na elaboração da cena. É essa atenção que possibilita perceber com mais acuidade a passagem do trágico ao melodramático envolvendo o destino de Béatrice, a qual, possuída pelo pai,

\footnotetext{
18 "Cenci va à la table et se verse un nouveau verre de vin. Plusieurs flambeaux s'éteignent tout d'un coup. On entend la voix devenue caverneuse des cloches. Un calme inouï tombe sur la scène. Quelque chose comme un son de viole vibre très légèrement et très haut".

19 "La musique s'agrandit. Une espèce de voix humaine désespérée se mêle maintenant à son rythme obsédant”.
}

TradTerm, São Paulo, v.38, fevereiro/2021, p. 46-60

Número Especial - III JOTA

www.revistas.usp.br/tradterm 
acaba cometendo o parricídio, num conjunto de ações que ecoam a definição de Patrice Pavis para o gênero:

O melodrama é a finalização, a forma paródica sem o saber, da tragédia clássica, cujo lado heroico, sentimental e trágico teria sido sublinhado ao máximo [...]. As situações são inverossímeis, mas claramente traçadas: infelicidade absoluta ou felicidade indizível; destino cruel que acaba ou se arranjando (no melodrama otimista) ou que permanece sombrio e tenso, como no roman noir [...]" (PAVIS 2008: 238-239).

Por tudo isso, a tradução de Les Cenci deve, antes de tudo, partir da observação minuciosa das rubricas enquanto dispositivos dos quais Artaud se vale, assim acredito, para o desenvolvimento ao mesmo tempo prático e teórico de suas ideias sobre o teatro.

A título de exemplo, podemos analisar uma breve passagem da peça. ${ }^{20}$ Num monólogo em que enuncia sua intenção de cometer o incesto, Cenci endereça sua confissão ao personagem que considera digno de guardar seu segredo:

\author{
Cenci \\ $[\ldots]$ \\ Il souffle dans l'air. \\ Air, je te confie mes pensées (ARTAUD 2011: 55).
}

A didascália sugere o movimento musical que deve conduzir a frase de Cenci. Em francês, souffler dans é empregado para descrever a ação de soprar um instrumento de sopro [instrument à vent] com o intuito de produzir algum som, isto é, de tocá-lo. Por exemplo, um instrumentista souffle dans une trompete (LE ROBERT 2020). Ao analisarmos a fala subsequente à rubrica em questão, percebemos que a mesma, após o endereçamento indicado anteriormente, inicia-se pelo pronome pessoal de primeira pessoa do singular em francês, 'je'. 0 uso da fricativa ' $j$ ' parece querer mimetizar a ação do souffle. É o mesmo procedimento que retorna ao final da frase pelo uso de

200 presente artigo, fruto de uma comunicação apresentada durante a $3^{a}$ Jornada de Tradução e Adaptação (JOTA) em novembro de 2019, não tem o objetivo de realizar uma tradução comentada de Les Cenci. Trata-se, antes, de refletir sobre os princípios que tal tarefa exigiria para, num segundo momento, realizá-la de fato.

$$
\begin{gathered}
\text { TradTerm, São Paulo, v.38, fevereiro/2021, p. 46-60 } \\
\text { Número Especial - III JOTA } \\
\text { www.revistas.usp.br/tradterm }
\end{gathered}
$$


uma nova fricativa, presente em pensées. As palavras são, assim, 'tocadas' por Artaud, o qual procura perfurar seus significados por meio da exploração expressiva de suas materialidades sonoras e musicais. A partir daí, podemos pensar numa possível tradução para a passagem em questão:

\author{
Cenci \\ [...] \\ Ele sopra o ar. \\ Ar, jogo a ti meus juízos.
}

Numa tradução literal, teríamos algumas possibilidades consideravelmente distintas do resultado acima. Entre as soluções mais óbvias num primeiro exercício, poderíamos pensar nas seguintes formas para a réplica de Cenci: Ar, te confio meus pensamentos; Ar, confio a ti meus pensamentos; Ar, confio meus pensamentos a ti. Em todas elas, perde-se o sopro inicial pelo desaparecimento da fricativa, substituída por oclusivas. 0 mesmo se dá com o final das três possibilidades propostas. Seja em 'pensamentos', seja em 'ti', a força das oclusivas se impõe na condução do desenvolvimento sonoro das frases. Pois, ainda que 'pensamentos' termine por uma fricativa, ao abrir a última sílaba, a oclusiva acaba por capturar expressivamente a palavra. Nesse sentido, ao retomarmos a tradução proposta, percebemos que a opção pelo vocábulo 'jogo' tenta, então, recuperar o movimento da frase de Artaud, iniciando a fala de Cenci pelo sopro da fricativa presente no original. Justificativa idêntica guiou a escolha do termo 'juízos'. Ainda que haja certa perda da força da tônica em pensées, a solução procura aproximar-se o máximo possível do souffle proposto por Artaud. Com isso, busca-se, como disse Augusto de Campos ao falar de suas traduções para alguns poemas de Rimbaud, "recriar, acima de tudo, a beleza estética do original" (CAMPOS 2002: 18). Dito de outro modo, a atenção à relação entre as didascálias e as réplicas dos personagens possibilita ao tradutor explorar a potência expressiva do fraseado artaudiano. Essa atenção permite perceber que o 'fracasso' de Les Cenci como expressão do ideal da crueldade não significa a ausência absoluta desta. Ao contrário, uma vez ciente desse jogo entre os dois registros textuais, o trabalho de tradução

TradTerm, São Paulo, v.38, fevereiro/2021, p. 46-60

Número Especial - III JOTA

www.revistas.usp.br/tradterm 
passa a ser um operador essencial de sua efetivação cênica ao manifestar a teatralidade singular da composição da peça.

Ao proceder por essa via, pode-se, como nos diz Ramos (1999: 17), “melhor vislumbrar a materialidade e a tridimensionalidade cênicas potenciais" que serviram ao laboratório da crueldade que a obra em questão procurou preparar, a despeito do que seriam suas insuficiências. A partir daí, o tradutor poderá elaborar um conjunto importante de ferramentas para as tomadas de decisão tradutórias em diálogo constante com as reflexões de Artaud, para quem,

O teatro só poderá voltar a ser ele mesmo, isto é, voltar a constituir um meio de ilusão verdadeira, se fornecer ao espectador verdadeiros precipitados de sonhos, em que seu gosto pelo crime, suas obsessões eróticas, sua selvageria, suas quimeras, seu sentido utópico da vida e das coisas, seu canibalismo mesmo se expandam, num plano não suposto e ilusório, mas interior (ARTAUD 2006: 104).

Como essa passagem deixa entender, para Artaud, a crueldade é o dispositivo pelo qual o teatro pode voltar a ofertar o "sentido utópico da vida", restituindo, pela "Palavra anterior às palavras”, a estrita relação entre esta e o pensamento, pois, nos lembra Blanchot, "Artaud nunca aceitara o escândalo de um pensamento separado da vida" (BLANCHOT 2005: 55).

Em Les Cenci, as didascálias aparecem, assim, como verdadeiros procedimentos de conexão entre essas duas instâncias, restituindo ao texto parte importante de sua eficácia cênica à qual o tradutor deve, impreterivelmente, prestar atenção, uma vez que, como argumento em outro artigo, "para que a tradução do texto de teatro não perca de vista suas especificidades, não poderíamos afastar seu caráter performativo" (IELPO 2018: 42).

TradTerm, São Paulo, v.38, fevereiro/2021, p. 46-60

Número Especial - III JOTA

www.revistas.usp.br/tradterm 


\section{Referências}

ArTaud, A. Les Cenci. Paris: Gallimard, 2011.

ARtaud, A. O teatro e seu duplo. Tradução de Monica Stahel e Teixeira Coelho. São Paulo: Martins Fontes, 2006.

ARTAUD, A. Antonin Artaud: œuvres. Paris: Gallimard, collection Quarto, 2004.

ARTAUD, A. "Carta de Antonin Artaud a Jean-Louis Barrault". In.: GuinsBurg, J. et al (orgs.). Linguagem $e$ vida: Antonin Artaud. São Paulo: Perspectiva, 1995, p.125-126.

Artaud, A. CEuvres Complètes V. Paris: Gallimard, 1964.

BARTHES, R. “Littérature et Signification”. In : CEuvres Complètes II. 2002, p. 508-525.

Blanchot, M. O livro por vir. Tradução de Leyla Perrone-Moisés. São Paulo: Martins Fontes, 2005.

Campos, A. Rimbaud Livre. São Paulo: Perspectiva, 2002.

Corvin, M. "Préface”. In.: Artaud, A. Les Cenci. Paris: Gallimard, 2011, p. 7-44.

DerRIDA, J. A escritura e a diferença. Tradução de Maria Beatriz Marques Nizza da Silva. São Paulo: Perspectiva, 1995.

Felício, V. L. A procura da lucidez em Artaud. São Paulo: Perspectiva / FAPESP, 1996.

IELPO, R. "A Tradução do Texto Teatral: Performances de uma Poética”. Revista da Anpoll, Florianópolis, $n^{\circ}$ 44, jan/abril, 2018, p. 41-50.

LE ROBERT. Dico en Ligne. Paris: Le Robert, 2020. Disponível em: <https://dictionnaire.lerobert.com/>. Acesso 12 jan. 2021.

PAVIS, P. Dicionário de teatro. Tradução de Jacó Guinsburg e Maria Lúcia Pereira. São Paulo: Perspectiva, 2008.

Ramos, F. L. O parto de Godot e outras encenações imaginárias. São Paulo: HUCITEC / FAPESP, 1999.

SonTAG, S. “Abordando Artaud”. In.: SonTAG, S. Sob o signo de saturno. Porto Alegre: L\&PM, 1986, p. 15-57.

Ubersfeld, A. Para ler o teatro. Tradução de José Simões. São Paulo: Perspectiva, 2005.

TradTerm, São Paulo, v.38, fevereiro/2021, p. 46-60

Número Especial - III JOTA

www.revistas.usp.br/tradterm 
VIRMAuX, A. Artaud e o teatro. Tradução de Carlos Eugênio Marcondes Moura. São Paulo: Perspectiva, 2009.

Willer, C. “Nota Biográfica”. In.: Willer, C. (Org.) Escritos de Antonin Artaud. Porto Alegre: L\&PM, 1983.

Recebido em: $14 / 03 / 2020$

Aceito em: 18/12/2020

Publicado em fevereiro de 2021

TradTerm, São Paulo, v.38, fevereiro/2021, p. 46-60

Número Especial - III JOTA

www.revistas.usp.br/tradterm 